\title{
Wind Speed and Solar Irradiance Variation Simulation Using ARMA Models in Design of Hybrid Wind-PV- Battery System
}

\author{
A. Kamjoo, A. Maheri, and G. Putrus
}

\begin{abstract}
Uncertainties in renewable energy resources are the main challenges in maintaining a high quality of supply in stand-alone Hybrid Renewable Energy Systems (HRES). Conventionally, a battery bank is used as an auxiliary source to reduce the vulnerability of HRES to the climate changes and maintain the desired quality of supply. Considering the uncertainties at the design stage would ensure appropriate sizing of the HRESs in order to improve their reliability under different operating conditions. This paper proposes a method in optimal sizing of a stand-alone wind turbine/PV/battery system considering uncertainties in renewable energy resources. The wind speed and solar irradiance variations are modelled by using time series analysis method. Performance of the design candidates is evaluated by using the Monte-Carlo simulation method. The analysis presented is supported by a case study for a typical household in the UK.
\end{abstract}

Index Terms-Stand-alone hybrid system, reliability, uncertainties, time-series analysis, monte-carlo simulation.

\section{INTRODUCTION}

Common drawback of using renewable resources is their unpredictable nature which is completely dependent on weather conditions and may result in load rejection at some points. In standalone Hybrid Renewable Energy Systems (HRES), the balance between demand and generation is obtained by an auxiliary power source such as a diesel generator or a battery bank.

Considering uncertainties when designing the system, could improve the HRES performance. For that, a realistic method is required to simulate the wind speed and solar irradiance variations. Different approaches are used to model the renewable sources behaviour. One of common approaches is fitting the uncertainties to known distributions such as Weibull or Beta distributions [1]. However researches show that, for some locations like UK using predefined distributions may not simulate the weather data properly [2]. Erken [3] used different distributions to find the best fitted distribution for each hourly meteorological data. Another method in considering uncertainties is adding a random disturbance to average values of wind speed and solar irradiance [4]. Lujano-Rojas [5] and Ji [6] used time series analysis to model and Time series analysis to model wind speed and solar irradiance variations accordingly. Time series could be a viable solution to model the

Manuscript received September 25, 2012; revised December 27, 2012.

The authors are with Faculty of Engineering and Environment, Northumbria University, NE1 8ST, UK. (e-mail: azadeh.kamjoo@northumbria.ac.uk, alireza.maheri@northumbria.ac.uk, ghanim.putrus@northumbria.ac.uk). uncertainties with unknown distributions.

This paper proposes a method in simulation of wind speed and solar radiation variations with time series analysis and Monte-Carlo simulation to design a stand-alone HRES. Here the historical hourly values of wind speed and solar irradiance are fitted to proper auto-regressive moving average (ARMA) models to simulate the uncertainties in wind speed and solar irradiance values. Using Monte-Carlo simulation method, design candidates are evaluated based on reliability and the system total cost. The latter is introduced as the optimum solution.

\section{THE WIND SPEED AND SOLAR IRRADIANCE SIMULATION MODEL}

In this paper the uncertainties in wind speed and solar irradiance is simulated using time series method. An ARMA model is fitted to historical meteorological data of each hour of a typical day of each month of the year. The output is used to simulate the variability in wind speed and solar irradiance data of each particular hour which will be used in Monte-Carlo simulation of design candidates.

\section{A. ARMA Model}

The mathematical formulation of ARMA is:

$$
y_{t}+a_{1} y_{t-1}+a_{2} y_{t-2}+\ldots+a_{p} y_{t-p}=\varepsilon_{t}+c_{1} \varepsilon_{t-1}+\ldots+c_{q} \varepsilon_{t-q}
$$

where $p$ and $q$ are ARMA model orders, $a_{1}, \ldots, a_{p}$ are the autoregressive parameters, $c_{1}, \ldots . c_{q}$ are the moving average parameters and $\varepsilon_{t}, \ldots, \varepsilon_{t-q}$ are random variables with mean value of zero and standard deviation of $\delta$.

The ARMA model orders and parameters are estimated as follow:

\section{1) Transformation of the historical data}

Transformation of input data is performed in order to stabilize the variance and make the data more normally distributed. Box-Cox transformation transforms nonnormally distributed data to a set of data that has approximately normal distribution.

if $\lambda$ is not zero:

$$
\operatorname{data}(\lambda)=\frac{\operatorname{data}^{\lambda}-1}{\lambda}
$$

if $\lambda$ is zero:

$$
\operatorname{data}(\lambda)=\log (\text { data })
$$




\section{2) Duckey-fuller test}

This test checks whether a unit root is present in autoregressive model. In case of the presence of unit root in the model the data would be non-stationary and needs to transform to a stationary data set by performing de-trending process.

\section{3) Order of ARMA model}

The order of ARMA model can be estimated using Akaike Information Criterion (AIC) and Final Prediction Error (FPE) [7]which measure the goodness of the fitted model by evaluation the models residuals.

$$
\begin{gathered}
A I C=\log \left[V\left(1+\frac{2 n}{N}\right)\right] \\
F P E=V \frac{1+n / N}{1-n / N}
\end{gathered}
$$

where $V$ is the variance of model residuals, $N$ is the length of the time series and $n=p+q$ is the number of estimated parameters in ARMA model.

\section{4) Ljung-box test}

Ljung-Box Test [8] is used to examine the existence of correlation between the fitted ARMA model residuals[9]. If the model is appropriate the $Q$ should be approximately distributed as $\chi^{2}$ with $m-p-q$ degrees of freedom.

$$
Q=N(N+2) \sum_{k=1}^{m} \frac{r_{k}^{2}}{N-k}
$$

where $N$ is the time series size, $r_{k}$ is the correlation if residuals at lag $k$. The null hypothesis is rejected if $Q$ is higher than chi-square distribution $\chi_{\alpha}^{2}(m-p-q)$.

\section{5) Simulation and back-transformation}

The data is simulated using fitted ARMA model and then back transformed to its original scale.

\section{Component AND Cost Modelling}

Different mathematical models have been proposed by researchers to estimate the output power of wind turbine, photovoltaic system and batteries. The models implemented in this study are chosen with consideration of giving a realistic estimation of the output of each system. Details on used models for wind turbine, PV panel, battery bank and cost can be found in [10].

\section{Problem Formulation AND DESIGN METHODOLOGY}

The objective is to find the optimum configuration of a standalone HRES with minimum total cost while satisfying the load demand at the desired reliability level. The reliability is measures by calculation the deficiency of power supply probability (DPSP).

The optimisation problem can be formulated as:

$$
\min T C=C_{I C}+C_{r e p}+C_{O \& M}
$$

while

$$
D P S P \leq D P S P_{\text {desired }}
$$

DPSP is the overall probability of deficiency in annual total power generated by the hybrid system and any configuration of hybrid system which satisfies above constraint is considered as feasible solution.

The design variables are the rotor swept area of wind turbine and area of PV panel.

The battery bank is sized using Equation (9):

$$
N_{\text {Bat }}=\frac{\operatorname{LoadS}_{D}}{C_{\text {Bat }} V_{\text {Bat }} D O D_{\text {max }} \eta_{\text {Bat }}}
$$

where Load is the load in (Wh); $S_{D}$ is the battery autonomy or storage days here considered as three days; $C_{B a t}$ is the battery bank nominal capacity in $(A h) ; V_{B a t}$ is the battery bank voltage in $(V) ; D O D_{\max }$ is the maximum depth of discharge and $\eta_{\text {Bat }}$ is the battery efficiency.

The performance of whole system is then simulated as:

$$
P_{\text {Total_HRES }}=\left\{\begin{array}{l}
P_{W T}+P_{P V}, \\
P_{W T}+P_{P V}+P_{\text {Bat }}
\end{array}\right.
$$

(a) if total power generated by wind turbine and PV is sufficient to cover the load demand otherwise,

(b) the battery supplies the difference $P_{B a t}$ as long as the state of charge the battery is:

$$
S O C \geq S O C_{\min }
$$

The reliability of each design candidate can be measured as [11]:

$$
D P S P=\frac{\sum_{i=1}^{8760} D P S_{i}}{\sum_{i=1}^{8760} P_{\text {load }_{i}}}
$$

where DPS is amount of deficiency in power supply at each hour.

Considering the uncertainties in renewable resources (modelled using times series analysis), the reliability of each HRES design candidate is analysed using Monte-Carlo simulation and the optimum solution with minimum total cost is selected among design candidates that satisfy the reliability constraint.

\section{CASE STUDAY}

The proposed method is used to design a stand-alone HRES for a household in Kent, UK. The input data for the design are typical summer and winter load profiles which are presented in Fig. 1 in addition to historical hourly data of wind speed and solar irradiance data for 12 months of the 
year. The ARMA parameters for wind speed and solar irradiance of each individual hour is estimated based on historical meteorological data for one typical day of each month. The output of ARMA simulation is used as hourly wind speed and solar irradiance in Monte-Carlo simulation. Examples of simulated wind speed and solar irradiance variations for a typical day in January are presented in Fig. 2, and Fig. 3.

The results of technical and economical characteristics of the system components are given in Table I.

The battery bank is sized based on three days of autonomy and the overall DPSP of the system is considered to be less than $D P S P_{\text {desired }}=15 \%$

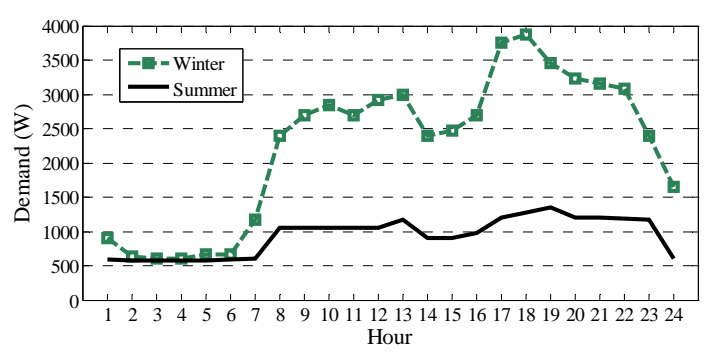

Fig. 1. Domestic Load Demand

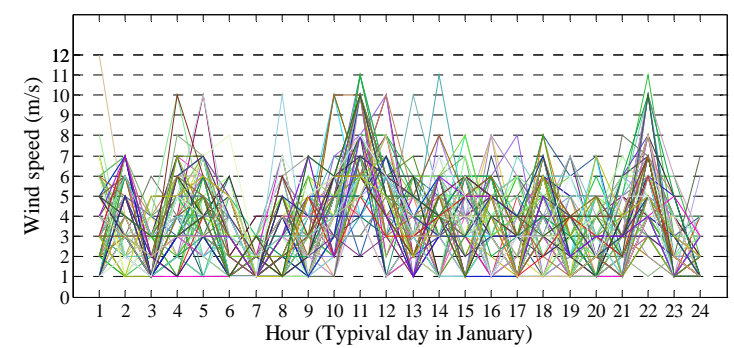

Fig. 2. An example of simulated wind speed

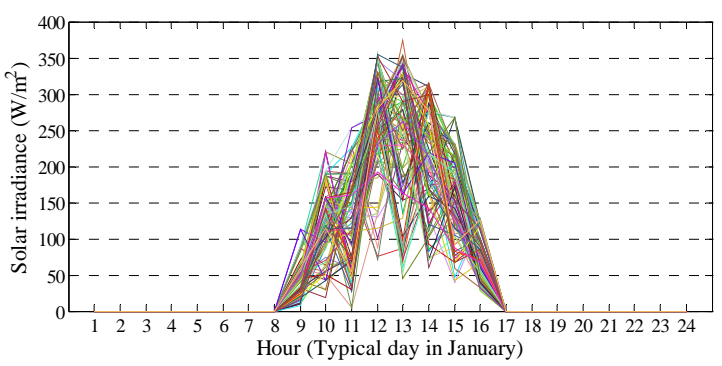

Fig. 3. An example of simulated solar irradiance

TABLE I: THE COMPONENTS DESIGN PARAMETERS

\begin{tabular}{|c|c|c|c|c|c|c|c|c|c|c|}
\hline Component & Efficiency (\%) & $\begin{array}{c}\text { Lifetime } \\
\text { (year) }\end{array}$ & Initial Cost & $0 \& M$ Cost & $\begin{array}{c}\text { Interest Rate } \\
(\%)\end{array}$ & $\begin{array}{c}\text { Inflation rate } \\
(\%)\end{array}$ & Nomial Capacity (Ah) & Nominal Voltage (V) & $\begin{array}{c}\text { Depth of } \\
\text { Discharge (\%) }\end{array}$ & Number of Cycles \\
\hline PV panel & 12.3 & 25 & $600(\$ / \mathrm{m} 2)$ & $1 \%$ of price & 8 & 4 & - & - & - & - \\
\hline WT & & 20 & $700(\$ / \mathrm{m} 2)$ & $3 \%$ of price & 8 & 4 & - & - & - & - \\
\hline Battery Bank & 90 & 8 & $1.5(\$ / \mathrm{Ah})$ & $1 \%$ of price & 8 & 4 & 40 & 24 & 90 & 535 \\
\hline
\end{tabular}

\section{RESUlts AND DisCUSSION}

In order to investigate the performance of modelling uncertainties with method explained in Section (II) in optimal design of HRES, an exhaustive search is performed to solve the optimisation problem Equation (7) The mean value of DPSPs obtained by performing 10,000 MonteCarlo simulations on each design candidate is considered as its overall DPSP and the optimum solution which satisfies the DPSP constraint with minimum total cost is introduced as the optimum solution.

Fig. 4 compares the upper and lower limits of DPSP values in different configurations of HRES. The optimum configuration is marked in Fig. 4

Fig. 5 and Fig. 6 show the values and the distribution of DPSP values for the optimum solution obtained using Monte-Carlo simulation.

The probability of blackout occurrence can be calculated using Monte-Carlo simulation result. The hours, when the battery bank is at its minimum state of charge or the overall available power of HRES is less than load demand, are counted as blackout hours. The probability of blackout occurrence is then calculated with:

$$
\text { Pr obability }_{\text {Blachout,Hour }}=\frac{n_{\text {Blackouts }}}{N_{\text {Simulations }}}
$$

Fig. 7 represents the probability of blackout occurrence in each day of the year for the optimum solution which is calculated with Equation (13). The figure clearly shows that the blackouts have strong probability to happen in the last three months of the year when renewable resources availability is not high enough to cover the load demand and charge the battery bank.

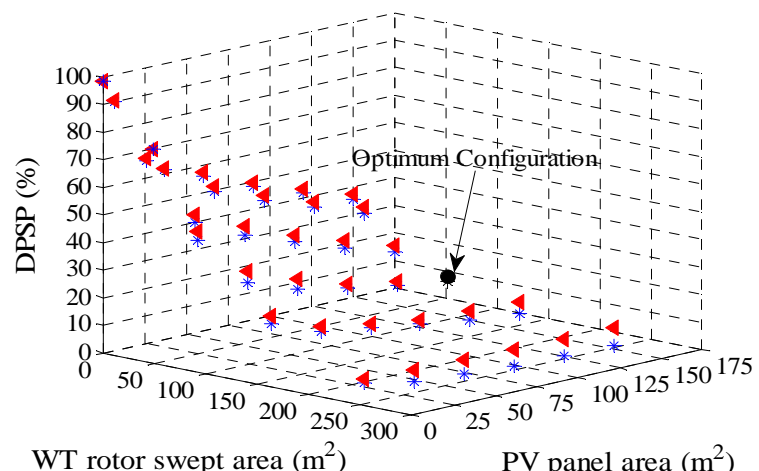

Fig. 4. Upper \& lower DPSP for design candidates

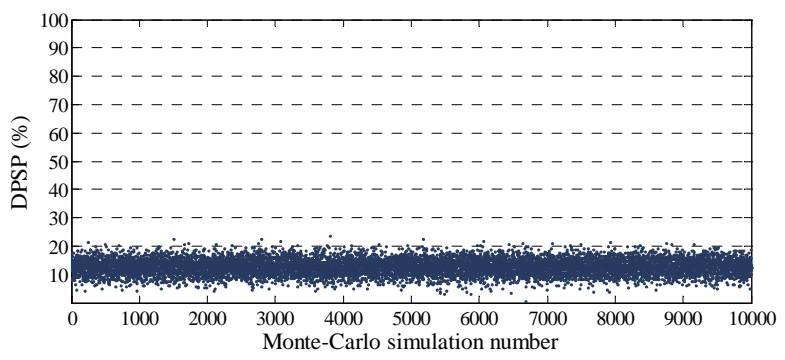

Fig. 5. DPSP values of optimum solution 


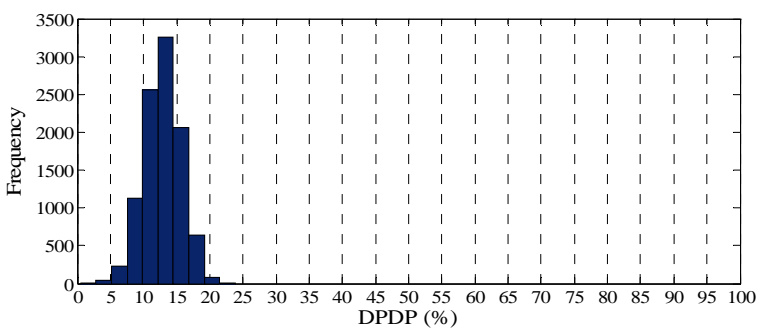

Fig. 6. Distribution of DPSP values for optimum solution

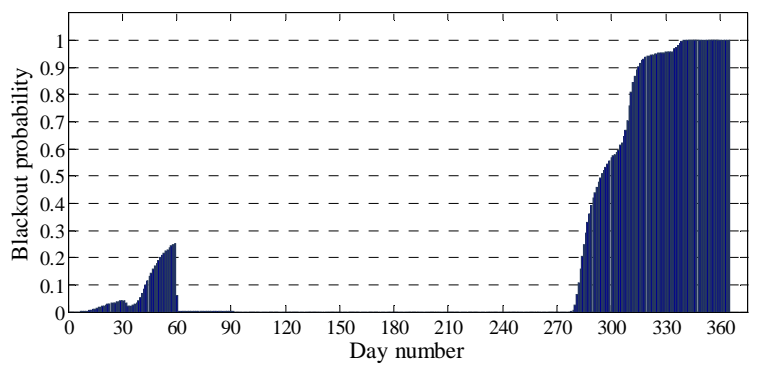

Fig. 7. Probability of blackout occurrence for each day of year

\section{CONCLUSION}

The Hybrid Renewable Energy System (HRES) can be a reliable solution to bring electricity to isolated areas where there is no access to the grid by considering uncertainties in resources at the design stage. Appropriate modelling of wind speed and solar irradiance variations, at the design stage, would give a more realistic picture of the designed system performance. This study shows that ARMA models can be used as a proper method in simulating the wind speed and solar irradiance data in design of HRES.

\section{ACKNOWLEDGMENT}

The financial support by Synchron Technology Ltd. through co-funding of this project is gratefully acknowledged.

\section{REFERENCES}

[1] S. H. Karaki, R. B. Chedid, and R. Ramadan, "Probabilistic Performance Assessment of Autonomous Solar-Wind Energy Conversion Systems," IEEE Transactions on Energy Conversion, vol. 14, 1999.

[2] A. M. Dizqah, A. Maheri, and K. Busawon, "An assessment of solar irradiance stochastic model for the UK," Environment Friendly Energies and Applications (EFEA) Symposium, pp. 670-675, 2012.

[3] B. Y. Ekren and O. Ekren, "Simulation based size optimization of a $\mathrm{PV} /$ wind hybrid energy conversion system with battery storage under various load and auxiliary energy conditions," Applied Energy, vol. 86, pp. 1387-1394, 2009.

[4] G. Giannakoudis, A. I. Papadopoulos, P. Seferlis, and S. Voutetakis, "Optimum design and operation under uncertainty of power systems using renewable energy sources and hydrogen storage,” International Journal of Hydrogen Energy, vol. 35, pp. 872-891, 2010.

[5] J. M. Lujano-Rojas, R. Dufo-LÃ ${ }^{3}$ pez, and J. L. Bernal-Agustãn, "Optimal sizing of small wind/battery systems considering the DC bus voltage stability effect on energy capture, wind speed variability, and load uncertainty,” Applied Energy, vol. 93, pp. 404-412, 2012.

[6] W. Ji and K. C. Chee, "Prediction of hourly solar radiation using a novel hybrid model of ARMA and TDNN," Solar Energy, vol. 85, pp. 808-817, 2011.

[7] H. Akaike, "Fitting autoregressive models for prediction," Ann. Inst.of Stat. Math., vol. 21, pp. 243-347, 1969.

[8] G. M. Ljung and G. E. P. Box, "On a Measure of a Lack of Fit in Time Series Models,” Biometrika, vol. 65, pp. 297-303, 1978.

[9] C. Chatfield, The Analysis of Time Series An Introduction, 6th ed.: Chapman \& Hall Texts in Statistical Science, 2004.

[10] A. Kamjoo, A. Maheri, and G. Putrus, "Reliability Criteria in Optimal Sizing of Stand-alone Hybrid Wind-PV-Battery bank System," Environment Friendly Energies and Applications (EFEA) Symposium, pp. 184 - 189, 2012.

[11] A. R. Prasad and E. Natarajan, "Optimization of integrated photovoltaic-wind power generation systems with battery storage," Energy, vol. 31, pp. 1943-1954, 2006.

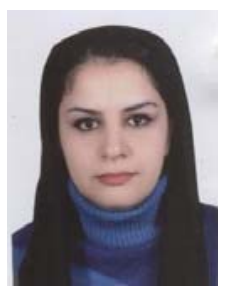

Azadeh Kamjoo received the degree in electrical engineering from the Khaje Nasir Toosi University of Technology, Tehran, Iran in 2001.

She has worked in industry for almost nine years. She is currently working toward the Ph.D. degree at the Faculty of Engineering and Environment, Northumbria University, Newcastle upon Tyne, UK. Her research interests are in stochastic optimization, hybrid renewable energy systems and power systems.

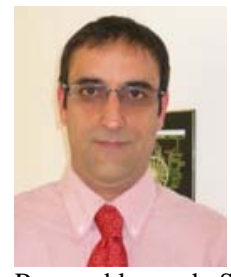

Alireza Maheri received his B.Sc. in Mechanical Engineering-Design from Shiraz University, Iran in 1991, his M.Sc. in Mechanical Engineering-Energy Conversion from Amirkabir University of Technology, Tehran-Iran in 1994 and his $\mathrm{PhD}$ in Computational Mechanics from UWE-Bristol, UK, in 2006.

$\mathrm{He}$ is currently senior lecturer in mechanical engineering and the programme leader for MSc Renewable and Sustainable Energy Technologies in the Faculty of Engineering and Environment, Northumbria University, Newcastle upon Tyne, UK.

Dr Maheri is a member of the editorial board of the Journal of Computational Methods and Experimental Measurements and has served as the organizer, member of steering committee and member of scientific advisory committee of several international conferences in the field of advanced materials and renewable energy including HPSM 2010, HPSM 2012, EFEA 2012 and Material Characterization 2013.

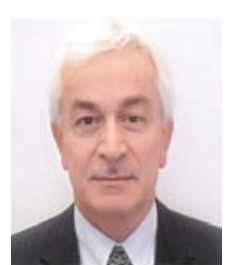

Ghanim Putrus received his B.Sc., M.Sc. and Ph.D. in electrical engineering from the University of Mosul, Mosul, Iraq and University of Manchester Institute of Science and Technology, UK in 1977, 1980 and 1990, respectively.

$\mathrm{He}$ is currently Reader in Electrical Power Engineering and leads the Power and Wind Energy Research (PaWER) group at Northumbria University, Newcastle upon Tyne, UK. His main research interests are the application of power electronics in power systems, power quality, integration of renewable energy sources and electric vehicles into power distribution networks (smart grids).

Dr. Putrus is a member of the IET Northumbria network committee, has served as chairman of the IET Northumbria branch for 2004/2005 session, also a member of the Editorial board for the Elsevier Renewable Energy Journal and has organized UPEC2006 conference at Northumbria. Dr Putrus is a member of the steering committees for several international conferences and has been involved in several research projects and has provided consultancies for industry. 